\title{
Targeted Perfusion Therapy in Spinal Cord Trauma
}

\author{
Samira Saadoun ${ }^{1} \cdot$ Marios C. Papadopoulos ${ }^{1}$ (D)
}

Published online: 8 January 2020

(C) The Author(s) 2020

\begin{abstract}
We review state-of-the-art monitoring techniques for acute, severe traumatic spinal cord injury (TSCI) to facilitate targeted perfusion of the injured cord rather than applying universal mean arterial pressure targets. Key concepts are discussed such as intraspinal pressure and spinal cord perfusion pressure (SCPP) at the injury site, respectively, analogous to intracranial pressure and cerebral perfusion pressure for traumatic brain injury. The concept of spinal cord autoregulation is introduced and quantified using spinal pressure reactivity index (sPRx), which is analogous to pressure reactivity index for traumatic brain injury. The Ushaped relationship between SPRx and SCPP defines the optimum SCPP as the SCPP that minimizes SPRx (i.e., maximizes autoregulation), and suggests that not only ischemia but also hyperemia at the injury site may be detrimental. The observation that optimum SCPP varies between patients and temporally in each patient supports individualized management. We discuss multimodality monitoring, which revealed strong correlations between SCPP and injury site metabolism (tissue glucose, lactate, pyruvate, glutamate, glycerol), monitored by surface microdialysis. Evidence is presented that the dura is a major, but unappreciated, cause of spinal cord compression after TSCI; we thus propose expansion duroplasty as a novel treatment. Monitoring spinal cord blood flow at the injury site has revealed novel phenomena, e.g., 3 distinct blood flow patterns, local steal, and diastolic ischemia. We conclude that monitoring from the injured spinal cord in the intensive care unit is a safe technique that appears to enable optimized and individualized spinal cord perfusion.
\end{abstract}

Key Words Blood pressure $\cdot$ critical care $\cdot$ decompression $\cdot$ dura $\cdot$ monitoring $\cdot$ spinal cord injury

Each year, about 23 million people worldwide have a traumatic spinal cord injury (TSCI) [1], which is a major, lifechanging event that leaves most people paralyzed or wheelchair bound. Apart from paralysis, TSCI also causes loss of sensation, loss of voluntary control of the urinary bladder and bowel, sexual dysfunction, and, in the case of cervical TSCI, impaired breathing and thermoregulation as well as hypotension. Other than the human suffering, there are economic implications; e.g., in the USA, the estimated lifetime cost of caring for a patient with severe cervical TSCI is estimated at $\$ 1,400,000$, excluding loss of income [2]. Currently, there is no treatment proven to improve outcome after TSCI [3]. Here, we discuss novel concepts that may improve the clinical management of acute TSCI.

Marios C. Papadopoulos

mpapadop@sgul.ac.uk

1 Academic Neurosurgery Unit, St. George's University of London, Cranmer Terrace, Tooting, London SW17 0RE, UK

\section{Current Management}

\section{Surgical}

After TSCI, patients are transferred to neurosurgical or orthopedic units and most undergo spinal surgery to correct deformity and stabilize the fractured spine by placing screws, plates, and rods. Several surgical controversies exist, e.g., anterior versus posterior approach, number of levels to be fixed, timing of surgery, and the role of laminectomy [4-10]; thus, operative management largely relies on surgeons' preferences rather than robust evidence. Substantial literature has been devoted to the timing and role of surgery; currently, most surgeons opt for early surgery, once the patient is medically stable $[8,10]$.

\section{Anesthetic and Medical}

TSCI is a multisystem disease that impairs ventilation and causes pulmonary infections (from diaphragmatic or intercostal muscle paralysis), bradycardia and hypotension (from 
damage to sympathetic cord pathways), as well as decubitus ulcers and deep venous thrombosis (from immobility) [11]. Patients with cervical or upper thoracic TSCI are generally admitted in intensive care units (ICUs) where there is wide variability in their management. For example, in the UK, the optimum blood pressure to maintain is unclear [4], whereas in the USA, the AANS/CNS joint guidelines are followed. These guidelines recommend maintaining mean arterial pressure (MAP) at $85-90 \mathrm{mmHg}$ for the first week after TSCI, but without robust evidence of benefit [12]. There is no consensus on the use of arterial or central venous lines during surgery and in ICU and in the type of vasopressor or anesthetic to be administered [4].

\section{Analogy with Traumatic Brain Injury}

The management of traumatic brain injury (TBI) fundamentally differs from the management of TSCI. Patients with severe TBI are intubated and transferred to an ICU where probes are inserted intracranially to monitor parameters such as intracranial pressure $(\mathrm{ICP})$, cerebral perfusion pressure $(\mathrm{CPP}=$ MAP minus ICP), vascular pressure reactivity index (PRx), optimum CPP $\left(\mathrm{CPP}_{\mathrm{opt}}\right)$, as well as injury site metabolites using microdialysis (MD), tissue oxygen, and spreading depolarizations $[13,14]$. Though the extent of monitoring varies between ICUs, 2 parameters (ICP and CPP) are a key to the TBI management and are commonly monitored [14]. The focus is to reduce ICP and increase CPP to prevent secondary brain damage from cerebral ischemia and brain herniation. There are several treatments to reduce ICP and increase CPP, e.g., osmotic diuretics, reducing arterial $\mathrm{pCO}_{2}$, increasing the dose of vasopressors, cerebrospinal fluid (CSF) drainage, hypothermia, barbiturates, evacuation of hematoma, and decompressive craniectomy [14-16]. These treatments are widely used in TBI patients, but their efficacy in TSCI is largely unexplored. Until recently, the lack of spinal cord monitoring in TSCI patients has made it impossible to evaluate the effect of such therapies on spinal cord physiology and metabolism.

\section{Monitoring Spinal Cord Pressure}

\section{Monitoring Technique}

In 2014, we described a technique (Fig. 1a-d) for placing a probe intradurally at the injury site to monitor the pressure of the injured cord as it is compressed against surrounding structures, which we termed intraspinal pressure (ISP) [17, 18]. We monitor ISP using the Codman ICP probe, because its cable is thinner and longer than that of other probes, e.g., Camino, and is licensed for use in humans. The probe is inserted intraoperatively during posterior surgical approach to the spine. Under the operating microscope, after laminotomy or laminectomy, the theca is perforated 1 spinal level below the injury with a $90^{\circ}$-angled needle to avoid damaging the underlying cord; the perforation is then widened with a blunt hook. The probe is tunneled into the wound, inserted through the thecal perforation, and advanced parallel to the cord to the point of maximal cord compression based on pressure measurements and the preoperative MRI. Several techniques reduce the risk of postoperative CSF leak and wound infection: The skin is sutured with nylon and sprayed with Opsite, a silk suture is used to tighten the skin around the probe, a wound drain is placed on
Fig. 1 ISP monitoring. (a) Schematic showing ISP probe between swollen cord and dura. (b) Intraoperative photo taken as an ISP probe was inserted intradurally. (c) Postoperative CT (d) Photo of computer screen showing monitored signals including ISP, ECG, ABP, and SCPP. SCPP is ABP minus ISP. (e) Enhanced visualization of SCPP versus time. SCPP (dark line). Range of optimal (green), intermediate (yellow), and suboptimal (red) SCPPs, with sPRx color scale. a

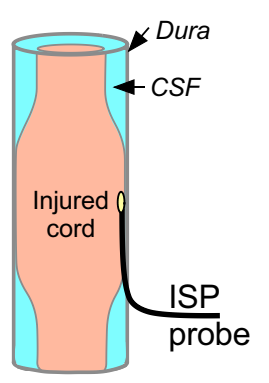

b

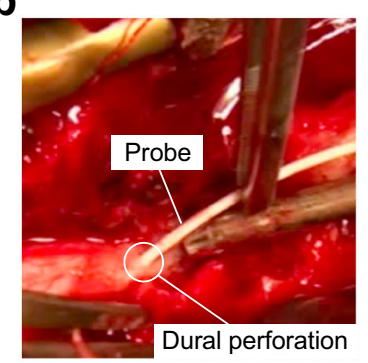

C

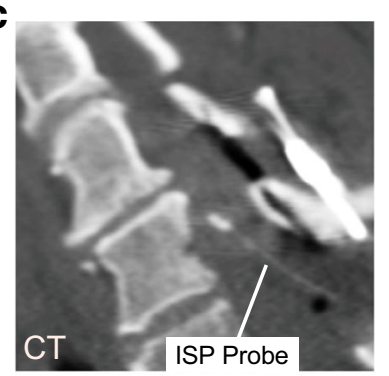

d

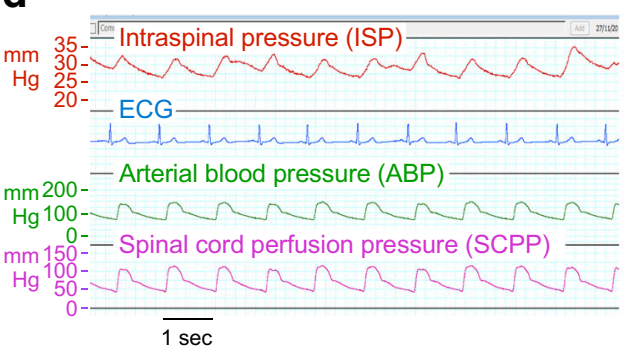

e

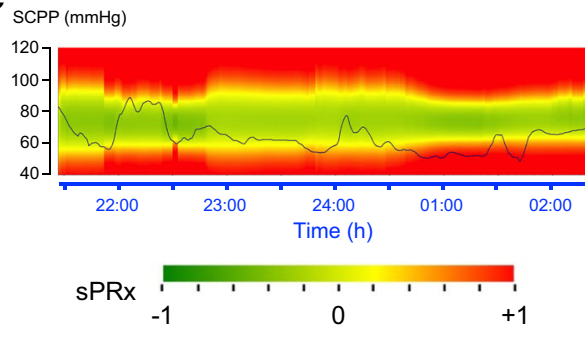


gravity to divert CSF away from the wound, and an Ioban drape is adhered over the wound and probe exit site. Data from 42 patients indicate that ISP monitoring is safe [19]. The major drawback of ISP monitoring is that the probe can only be inserted during a posterior surgical approach. Depending on the location of the spine fracture and the surgeon's preference, acute spinal decompression and fusion may be done from an anterior approach, which would preclude probe insertion.

\section{Physiological Parameters}

The ISP waveform is similar to ICP with 3 characteristic peaks (P1 percussion, $\mathrm{P} 2$ tidal, $\mathrm{P} 3$ dicrotic) and comparable Fourier spectra that have prominent cardiac and respiratory peaks. By analogy with CPP for TBI, in the TSCI patients, we compute the spinal cord perfusion pressure (SCPP) as MAP-ISP (Table 1). SCPP more accurately measures cord perfusion than the currently used MAP because patients with the same MAP have different SCPPs depending on ISP. Aiming to optimize SCPP, rather than MAP, in TSCI is the first step towards individualized patient management.

\section{Optimum SCPP}

We applied the concept of vascular pressure reactivity, based on the autoregulation curve for brain [20], to the injured cord to obtain the spinal pressure reactivity index (sPRx) as the running correlation coefficient between ISP and MAP [17, 18]. $s P R x$ ranges from -1 to $+1 ; s P R x \leq 0$ indicates intact vascular reactivity, whereas $\mathrm{SPRx}>0$ indicates impaired reactivity. sPRx plotted against SCPP, using data from several TSCI patients, yields a U-shaped curve, which defines the optimum SCPP ( $\mathrm{SCPP}_{\text {opt }}$ ) as the SCPP that minimizes SPRx and is similar to the PRx versus CPP plot for TBI $[17,18,21]$. The concept of $\mathrm{SCPP}_{\text {opt }}$ is clinically important because it suggests that not only hypoperfusion but also hyperperfusion at

Table 1 Comparison of physiological parameters in TSCI and TBI

\begin{tabular}{ll}
\hline TSCI & \\
ISP & Intraspinal pressure \\
SCPP & Spinal cord perfusion pressure \\
sPRx & Spinal pressure reactivity index \\
sRAP & Spinal compensatory reserve \\
SCPP $_{\text {opt }}$ & Optimum spinal cord perfusion pressure \\
TBI & \\
ICP & Intracranial pressure \\
CPP & Cerebral perfusion pressure \\
PRx & Pressure reactivity index \\
RAP & Compensatory reserve \\
CPP & Opt \\
\hline
\end{tabular}

$\mathrm{TBI}=$ traumatic brain injury; $\mathrm{TSCI}=$ traumatic spinal cord injury the injury site may be detrimental. Potential mechanisms of hyperperfusion-induced cord injury include cord swelling, cord hemorrhage, and a local steal phenomenon [22].

SPRx versus SCPP plots for individual patients, rather than pooled patient data, yield $\mathrm{SCPP}_{\text {opt }}$ values that differ markedly, by up to $60 \mathrm{mmHg}$, between patients [23]. The patientdependent $\mathrm{SCPP}_{\mathrm{opt}}$ suggests that individualized patient management is required to achieve targeted perfusion therapy. This makes sense because several factors, which differ between TSCI patients, likely determine $\mathrm{SCPP}_{\text {opt }}$, e.g., level and mechanism of injury, extent of microvascular damage, tissue ischemia, tissue acidosis, and pre-TSCI baseline blood pressure. Two further modifications were introduced to refine the concept of $\mathrm{SCPP}_{\text {opt }}$ : First, since many $\mathrm{SCPP}_{\text {opt }}$-determining factors vary with time (e.g., cord ischemia, edema, or acidosis), $\mathrm{SCPP}_{\text {opt }}$ must also vary with time in each patient. Second, there is often a range of SCPPs, rather than a single value (minimum of the SPRx versus SCPP curve), associated with intact autoregulation. We thus extended the concept of $\mathrm{SCPP}_{\text {opt }}$ to represent a range of pressures, computed from a sliding window of the preceding $4 \mathrm{~h}$, updated each minute [23]. An enhanced display technique allows the SCPP and $\mathrm{SCPP}_{\text {opt }}$ to be visualized in real time in a clinically meaningful way on the ICU monitors (Fig. 1e) [23]. Future studies are required to allow computation of $\mathrm{SCPP}_{\text {opt }}$ using a time window shorter than $4 \mathrm{~h}$ so that the injured cord is not exposed to a long course of ischemia before treatment is initiated.

The main drawback of a continuous $\mathrm{SCPP}_{\text {opt }}$ is that the SCPP has to vary widely within each 4-h window to define both arms of the U-shaped sPRx versus SCPP curve. The concept of a real-time $\mathrm{SCPP}_{\text {opt }}$ range for TSCI is analogous to the concept of a real-time $\mathrm{CPP}_{\text {opt }}$ for TBI $[24,25]$. There is now strong evidence that $\mathrm{CPP}_{\text {opt }}$ correlates with outcome. One study [25] divided patients with acute TBI into 3 groups: those managed with CPP close to $\mathrm{CPP}_{\text {opt }}$ (group 1), those managed with CPP lower than $\mathrm{CPP}_{\text {opt }}$ (group 2, ischemia), and those managed with $\mathrm{CPP}$ greater than $\mathrm{CPP}_{\text {opt }}$ (group 3, hyperemia). Compared with group 1 patients, those in group 2 had higher mortality and those in group 3 had higher disability. Further work from large numbers of patients is needed to validate the concepts of ISP, SCPP, sPRx, continuous $\mathrm{SCPP}_{\text {opt }}$, etc., and to determine whether upward and downward deviations of SCPP from $\mathrm{SCPP}_{\mathrm{opt}}$ are associated with worse neurological outcome.

\section{Complexity of ISP Signal}

For a simple introduction to the concepts described in this section including complexity, edge-of-chaos dynamics, detrended fluctuation analysis, and multiscale entropy (MSE), the reader is referred to the presentation in the supplement that accompanies the article by Chen et al. [26]. The ISP signal is complex because it is influenced by many local and systemic factors that interact over different timescales, e.g., 
spinal cord blood flow (SCBF), tissue oxygen, tissue metabolism, and cardiac and respiratory pulsations. Complexity is a fundamental property of healthy biological systems that renders them resistant to external stress $[27,28]$. Complex biological signals are characterized by self-affinity and "edge-ofchaos" dynamics. Edge of chaos means that systems transition between order and disorder, which, unlike periodicity or randomness, facilitates self-organization, evolution, and adaptability [29-33]. After TSCI, factors influencing the ISP signal become disrupted with more severe TSCIs causing more severe disruption; therefore, TSCI may be viewed as a loss of ISP signal complexity.

The nonlinear ISP dynamics can be quantified by computing hourly the detrended fluctuation exponent $\alpha[29,30]$, the MSE [31, 32], and the maximal Lyapunov exponent $\lambda_{\max }$ [33]. Such analyses revealed that pathological processes at the injury site including cord swelling (high ISP), hypoperfusion (low SCPP), or impaired pressure reactivity (high sPRx) were associated with increased $\alpha$ and decreased MSE, which render the cord less adaptable to external changes [26]. Increased $\alpha$ indicates disrupted fractality, and decreased MSE indicates decomplexification of the ISP signal. We found negative correlations between the $\%$ of hours with edge-of-chaos dynamics $(-0.01 \leq \lambda \leq 0.01)$ versus high ISP and versus low SCPP [26]. This means that secondary insults render the ISP more regular or chaotic [26]. In a multivariate logistic regression model, better neurological status on admission, higher ISP MSE, and more frequent edge-of-chaos ISP dynamics predicted long-term functional improvement. To further access the hidden information within the complex fluctuations of the ISP signal, we mapped each ISP time series into a visibility graph [34] and quantified the topology of these graphs using concepts from complex network theory such as diameter, modularity, eccentricity, and small worldness [35]. Our data show that the topological structure of ISP graphs is highly sensitive to adverse events at the injury site, e.g., cord compression (increased ISP), hypoperfusion (reduced SCPP), and impaired vascular pressure reactivity (increased sPRx). These findings suggest that ISP signals contain clinically important information hidden within the complex signal fluctuations, not accessible with conventional signal analysis.

\section{ISP Versus Lumbar Cerebrospinal Fluid Pressure}

Early attempts to obtain real-time information from the injured cord to guide management involved monitoring cerebrospinal fluid pressure (CSFP) by inserting a lumbar catheter [36] rather than monitoring ISP from the injury site [18]. Unlike pressure probes, which require surgery to place them at the injury site, lumbar catheters are widely used and easily introduced in the ICU or on the wards.

To find out whether lumbar CSFP is the same as ISP, we simultaneously monitored CSFP and ISP in 13 patients with severe TSCI and concluded that the 2 techniques yield markedly differ values for cord pressure (ISP $\neq$ CSFP), perfusion pressure $\left(\mathrm{SCPP}_{\mathrm{ISP}} \neq \mathrm{SCPP}_{\mathrm{CSF}}\right)$, and pressure reactivity $\left(\mathrm{sPRx}_{\mathrm{ISP}} \neq \mathrm{sPRx} \mathrm{XSS}_{\mathrm{CSF}}\right)$ [37]. CSFP was nonpulsatile $21 \%$ of the time or had simple waveforms, whereas ISP was always pulsatile with waveforms that had the characteristic P1-P2-P3 peaks. The running correlation coefficient between ISP and CSFP was $>0.7$ for $>75 \%$ of the time in $23 \%$ of patients, 25 $75 \%$ of the time in $23 \%$ of patients, and $<25 \%$ of the time in $54 \%$ of patients. The extent of cord edema on MRI inversely correlated with the ISP versus CSFP correlation coefficient. Together, these observations suggest that cord compression against the surrounding dura may be dynamic: During periods when there is CSF around the injured cord, which indicates no compression, ISP $\approx$ CSFP, but when the injured cord becomes compressed against the dura, ISP $\neq$ CSFP (Fig. 2). The idea that cord compression against the dura at the injury site renders ISP $\neq$ CSFP is also supported by waveform analysis, which revealed significantly steeper $\delta \mathrm{P} / \delta \mathrm{T}$ slope for ISP than CSFP and delay, by $>100 \mathrm{~ms}$ in most cases, between the onset of the CSFP pulse and that of the corresponding ISP pulse. These findings suggest that ISP is measured in a solid compartment (injured cord compressed against dura), whereas CSFP is in a liquid compartment. The conclusion from these studies is that ISP monitoring more accurately represents the injury site than lumbar CSFP monitoring. Lumbar CSFP monitoring may still be clinically helpful because the $\mathrm{SCPP}_{\mathrm{CSFP}}$, computed as MAP-CSFP, better correlates with outcome after TSCI than the MAP [38].

\section{Therapies Based on ISP Monitoring}

\section{Reducing ISP and Increasing SCPP}

Several maneuvers to reduce ISP or increase SCPP have been investigated (Table 2) [18]. Reducing arterial $\mathrm{pCO}_{2}$ and altering the dose of the anesthetic sevoflurane or i.v. mannitol administration did not significantly affect ISP or SCPP. Increasing the dose of epinephrine increased MAP and consequently increased SCPP. Drainage of $10 \mathrm{~mL} \mathrm{CSF}$ via a lumbar catheter did not significantly alter ISP in 58\% of patients, significantly reduced ISP by $<5 \mathrm{mmHg}$ in $33 \%$ of patients, and only significantly reduced ISP by $9 \mathrm{mmHg}$ in $9 \%$ of patients [37]. Therefore, the only nonsurgical technique to reliably increase SCPP is to increase the MAP with vasopressors. The role of surgery (expansion duroplasty) in reducing ISP and increasing SCPP is discussed below.

Intervening to increase SCPP appears beneficial because it increases the amplitude of motor-evoked potentials [18] or somatosensory-evoked potentials [41] at or across the level of injury in most patients, lowers the sensory level in some 
Fig. 2 ISP versus lumbar CSFP. (a) ISP $\neq$ CSFP when the injured cord is swollen and compressed against the dura. (b) ISP $\approx$ CSFP when there is CSF around the injured cord.

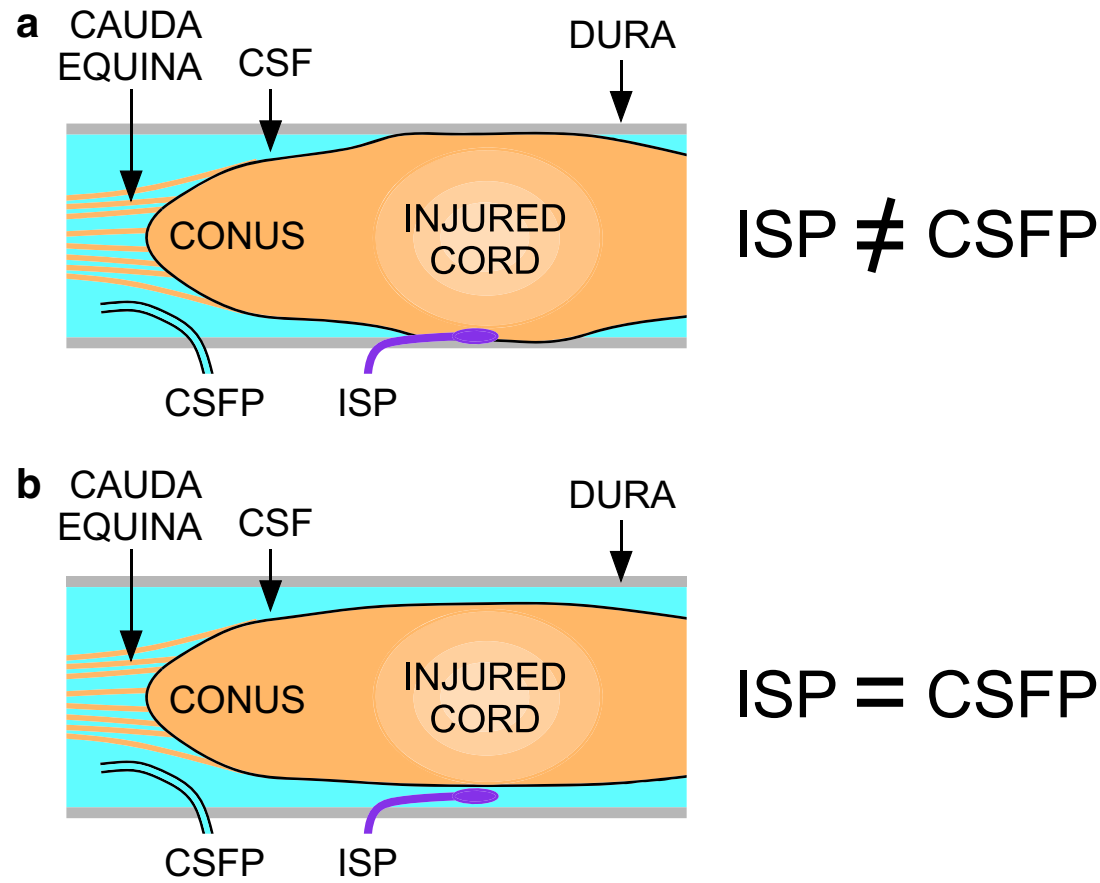

patients [42], and improves limb motor responses in some American Spinal Injury Association Impairment Scale (AIS) grade C patients [18]. The chance of AIS grade conversion at 9-12 months after the TSCI negatively correlates with the mean ISP on admission and positively correlates with the mean SCPP on admission (Fig. 3) [43]. Increasing SCPP presumably reduces ischemia at the injury site. Though it is unclear whether overincreasing SCPP, such that SCPP > $\mathrm{SCPP}_{\text {opt }}$, worsens neurological outcome, these findings suggest that ISP and SCPP are key physiological parameters that are strongly linked to neurological status after TSCI.

\section{Expansion Duroplasty}

A consistent finding from ISP monitoring is compartmentalization at the injury site (Fig. 4a), which occurs because the swollen cord becomes compressed against the dura, even after adequate bony decompression [44, 45]. This is evident when monitoring pressure from several sites simultaneously, e.g., injury site (ISP), CSF compartment below, and extradural compartment: Each compartment has a different pressure $[18,46]$. In an AIS grade A thoracic TSCI patient, we advanced the pressure probe intradurally, from distal to the

Table 2 Effect of different maneuvers in TBI versus TSCI

\begin{tabular}{|c|c|c|c|}
\hline Maneuver & TBI & TSCI & TSCI Ref. \\
\hline $\begin{array}{l}\text { Reducing arterial } \mathrm{pCO}_{2} \\
\quad \text { (hypercapnia to normocapnea) }\end{array}$ & Reduces ICP, increases CPP & No effect on ISP or SCPP & {$[18]$} \\
\hline Reducing sevoflurane dose & Reduces ICP & No effect on ISP or SCPP & {$[18]$} \\
\hline Mannitol & Reduces ICP, increases CPP & No effect on ISP or SCPP & {$[18]$} \\
\hline Hypertonic saline & Reduces ICP, increases CPP & Not tested & N/A \\
\hline Vasopressors (epinephrine) & Increases MAP, thus increasing CPP & Increases MAP, thus increasing SCPP & {$[18]$} \\
\hline CSF drainage & Reduces ISP, increases CPP & $\begin{array}{l}\text { Little or no effect on ISP or SCPP in } \\
\text { severe TSCI with cord compressed } \\
\text { against dura }\end{array}$ & {$[37]$} \\
\hline Surgical decompression & Reduces ISP, increases CPP, reduces mortality & $\begin{array}{l}\text { Bony decompression controversial, } \\
\text { bony }+ \text { dural decompression } \\
\text { (expansion duroplasty reduces ISP } \\
\text { and increases SCPP) }\end{array}$ & {$[39,40]$} \\
\hline
\end{tabular}

$\mathrm{CPP}=$ cerebral perfusion pressure; $\mathrm{CSF}=$ cerebrospinal fluid; $\mathrm{ICP}=$ intracranial pressure; $\mathrm{ISP}=$ intraspinal pressure; $\mathrm{MAP}=$ mean arterial pressure; $\mathrm{N} / \mathrm{A}$ = not applicable; Ref. = references; SCPP = spinal cord perfusion pressure; TBI = traumatic brain injury; TSCI = traumatic spinal cord injury 
a

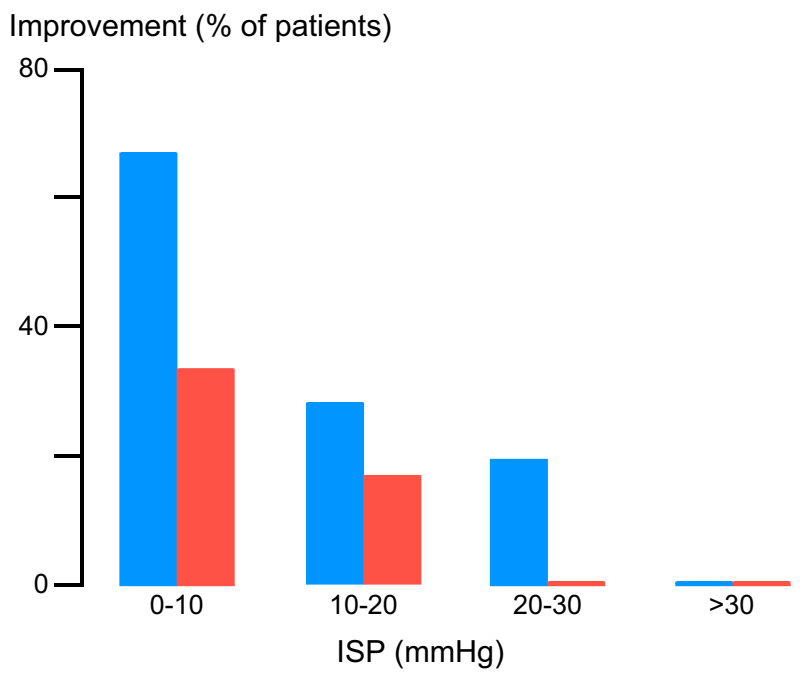

b

Improvement (\% of patients)
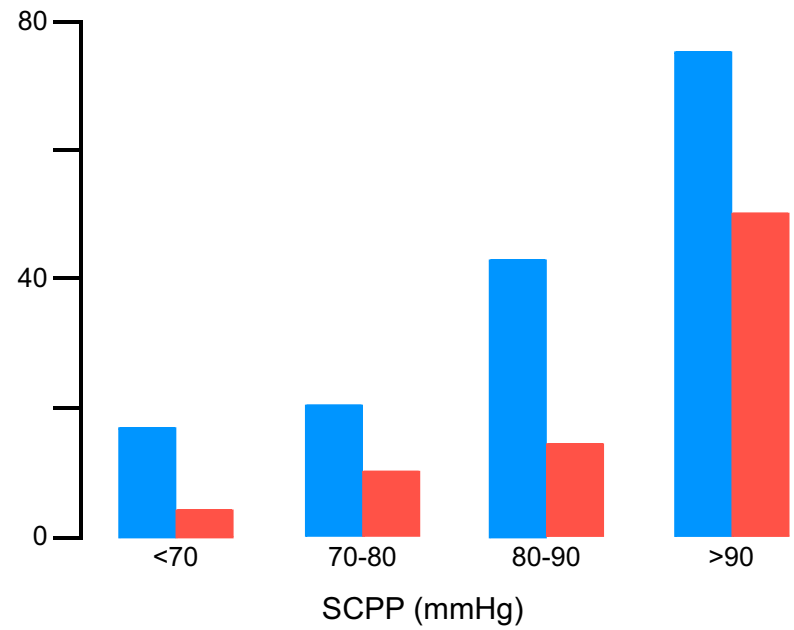

Fig. 3 ISP and SCPP versus outcome. (a) Mean ISP and (b) mean SCPP versus $\%$ of patients that improved by at least 1 (blue) or at least 2 (red) AIS grades. Follow-up for 9-12 months.

injury site to proximal, thus defining a pressure profile with maximal pressure at the injury site [44]. Dural cord compression is also evident on MRI; in TSCI patients who had serial scans, the extend of dural cord compression resolves slowly with $t_{1 / 2} \approx 9$ days [47]. These observations suggest that the dura may play a major, but unappreciated, role in spinal cord compression after TSCI.

The idea that the dura causes CNS compression is established in TBI; thus, decompressive craniectomy involves removing skull and opening dura to allow outward herniation of brain to reduce ICP and increase CPP [16, 39]. In a randomized controlled trial, decompressive craniectomy significantly reduced mortality though most surviving patients had severe disabilities [16]. In the context of TSCI, decompression has a different meaning from the term "decompression" for TBI. In TSCI, decompression refers to restoring normal spinal alignment and removing bony fragments or hematoma compressing the theca, i.e., extradural decompression that fails to appreciate that the cord is swollen against dura. Thus, to effectively decompress the injured cord, expansion duroplasty may be required in addition to bony decompression (Fig. 4b-d). In a pilot study, expansion duroplasty took 10-15 $\mathrm{min}$ to perform and was safe [48]. Compared with laminectomy in 11 TSCI patients, laminectomy + duroplasty in $10 \mathrm{TSCI}$ patients reduced ISP by $\sim 10 \mathrm{mmHg}$ and increased SCPP by $\sim 15 \mathrm{mmHg}$, on average. In the duroplasty group, $10 \%$ of patients had CSF leak, easily eliminated by placing extra sutures in ICU, and $50 \%$ of patients had noncompressive pseudomeningocele that disappeared by 6 months on MRI. Based on these findings, we plan a randomized controlled trial of expansion duroplasty for acute, severe TSCI.

\section{Enhancing Drug Delivery}

Several trials of neuroprotective agents for TSCI have failed, despite evidence from different TSCI animal models that the drugs are neuroprotective [49-51]. In 3 TSCI patients, we injected intravenously a 4-mg bolus of dexamethasone and found that little $(\sim 0.64 \%$, based on area under the curve calculations) dexamethasone entered the injury site [52]. The penetration of intravenously administered dexamethasone into the injured spinal cord was increased 3-fold by increasing the SCPP by $10 \mathrm{mmHg}$. This finding may explain why neuroprotective drug trials have failed: In TSCI patients,- the drug is often given in suboptimal conditions, e.g., during hypotension, which is frequently associated with cervical spinal cord injuries, thus limiting drug penetration into the injured cord. Optimization of SCPP is a prerequisite for maximizing drug delivery at the site of injury.

\section{Managing Fever}

Fever is observed in up to $67 \%$ of patients with acute TSCI and may arise from infection or be neurogenic [53-56]. In TSCI patients, fever was associated with significantly more deranged metabolite levels than normothermia evidenced by lower tissue glucose, higher lactate, higher glutamate, and higher lactate-to-pyruvate ratio (LPR, a measure of anaerobic metabolism) [57]. Fever was particularly detrimental on injury site metabolism when the peripheral white cell count was high, which suggests that fever associated with infection may be more detrimental than neurogenic fever. In 2 TSCI patient cohorts, managed in London and Berlin [57], high fever burden correlated with less neurological improvement. Though further studies are required to determine the effect and temporal relations between the different types of fever (infection, neurogenic) and injury site metabolism, based on the data to date, we suggest prompt treatment of fever in TSCI patients 
Fig. 4 Dural cord compression and duroplasty. (a) MRI (left) and schematic (right). The swollen cord is compressed against the dura causing 4 compartments: intrathecal above (blue), extrathecal (yellow), intrathecal at injury site (purple), and intrathecal below (green). (b) Intraoperative photo of expansion duroplasty. (c) ISP (mean \pm S.D.) and (d) SCPP (mean \pm S.D.) versus days after injury for 11 patients who had bony decompression + stabilization and 10 patients who had bony + dural decompression + stabilization. a

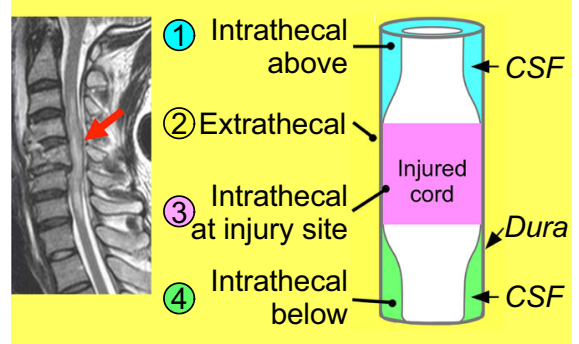

C ISP $(\mathrm{mmHg})$

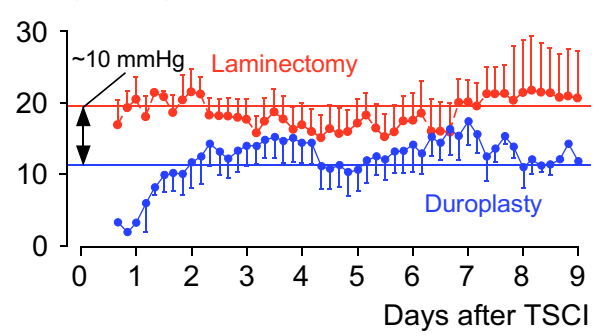

b

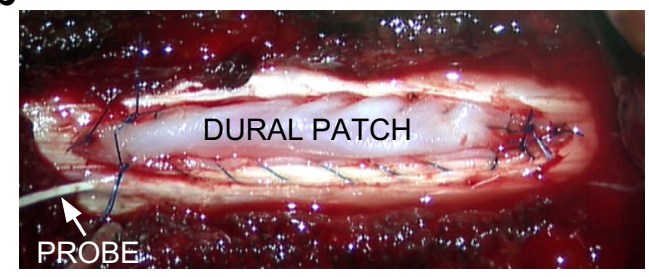

d SCPP $(\mathrm{mmHg})$

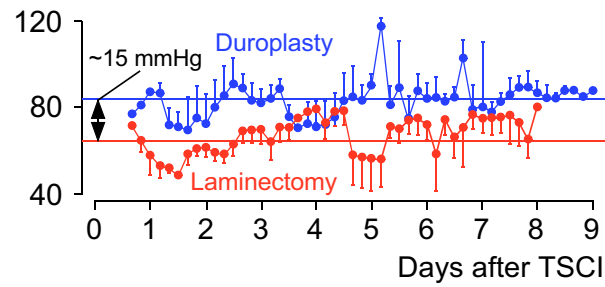

with paracetamol, nonsteroidal anti-inflammatory drugs, or active cooling.

\section{Hypothermia}

Hypothermia is being investigated as a potential therapy for TSCI [58] based on data that hypothermia is neuroprotective in animal models by targeting many pathological processes, e.g., reducing metabolic rate, inflammation, edema, oxidative stress, excitotoxicity, electrolyte imbalance, as well as apoptotic and necrotic cell death in damaged CNS tissue [59-66]. Despite the encouraging findings of animal studies, randomized controlled human trials have failed to show functional benefit of hypothermia in human TBI [67-69]. Though small, nonrandomized studies of TSCI patients suggest improved outcome after local $[70,71]$ or systemic $[58,72]$ hypothermia, there are no published randomized controlled trials of hypothermia for TSCI. A major problem with hypothermia is the paucity of mechanistic data from humans regarding the effect of cooling and rewarming on cord swelling, metabolism, and inflammation. It is thus unclear if hypothermia and rewarming have beneficial or adverse effects on the injured human spinal cord. In a study of 5 TSCI patients, a local cord hypothermia-rewarming protocol was applied. Cooling did not affect cord physiology (no change in ISP or SCPP) but markedly altered cord metabolism (increased glucose, lactate, LPR, and glutamate and decreased glycerol) and markedly reduced cord inflammation (reduced IL-1 $\beta$, IL-8, monocyte chemoattractant protein (MCP), macrophage inflammatory protein (MIP)-1 $\alpha$, MIP-1 $\beta$ ).
Rewarming significantly worsened cord physiology (increased ICP, decreased SCPP), cord metabolism (increased lactate and LPR, decreased glucose and glycerol), and cord inflammation (increased IL-1 $\beta$, IL-8, IL-4, IL-10, MCP, MIP-1 $\alpha$ ). Based on these findings, we suggest that spinal cord monitoring be employed in hypothermia studies to provide real-time information about the impact of temperature changes on spinal cord physiology and metabolism.

\section{Nursing Care}

Nursing care after TSCI involves avoiding decubitus ulcers by frequent patient turning. Our work has shown that, after a laminectomy, external forces applied to wound are transmitted to the swollen, injured cord, causing an increase in ISP and a decrease in SCPP, thus potentially inflicting cord damage [18]. This arises because of the lack of CSF around the cord that would normally buffer the compression forces and may be important in supine patients with mid-thoracic TSCI that have a pillow placed between their shoulders [19]. Ways to prevent damaging the injured cord from external forces include avoiding wound compression and placing cross-links between the rods used to stabilize the spine.

\section{Multimodality Monitoring}

Multimodality monitoring for TBI is based on the idea that secondary damage arises not only from altered perfusion but also from other factors such as acidosis, excitotoxicity, tissue hypoxia, and aberrant electrical activity. Thus, in TBI patients, 
some ICUs monitor not only ICP and CPP but also tissue metabolism (hourly tissue glucose, lactate, pyruvate, LPR, glutamate, glycerol) using MD [73], tissue oxygen using a Licox probe [74], hemoglobin saturation using near-infrared spectroscopy [75], and spreading depolarizations using electrode arrays [76].

\section{Microdialysis}

In TBI, there is substantial evidence that derangement of tissue metabolism correlates with outcome [73]. We have recently reported a technique to monitor spinal cord metabolism after TSCI with surface MD (Fig. 5) [52]. Studies in pigs show that surface and intraparenchymal MD give comparable metabolite values in the pulsating heart [77] and liver [78]. For spinal cord, surface MD at the injury site differs markedly from corresponding measurements taken from the lumbar CSF [37]. The key findings of our study are that SCPP strongly correlates with injury site metabolic profile and that the extent of metabolic derangement and the probability of AIS grade conversion after TSCI correlate well with the degree of metabolic derangement at the injury site.

A problem with multimodality monitoring is interpretation of the large volumes of data in a clinically meaningful way. In TSCI patients, we analyzed the MD data using Kohonen selforganizing maps and discovered 3 metabolic patterns termed near-normal, ischemia/necrosis, hyperemia, and distal [79]. "Big data analytics," currently under development to extract conclusions from large datasets [80], could be applied to evaluate multimodality data. Additional techniques, e.g., Granger [81] or Sugihara [82] causality analysis, which quantify directions of information flow in time series may also be useful. Suppose there is an increase in LPR, fall in tissue oxygen, and rise in ISP. Causality analysis may be used to determine whether the rise in ISP caused the fall in tissue oxygen, which, in turn, caused the rise in LPR. Knowing the direction of information flow is clinically useful to differentiate between cause and effect. Further studies are awaited in TSCI patients to determine the clinical value of additional monitoring from the injury site including tissue oxygen and spontaneous electrical activity.
Fig. 5 Multimodality monitoring after TSCI. (a) Setup for ISP + microdialysis monitoring: i) microdialysis catheter, ii) microdialysis analyzer, iii) intraoperative photo showing ISP probe + microdialysis catheter, and iv) postoperative $\mathrm{CT}$ showing ISP probe + microdialysis catheter. (b) LPR (left) and glutamate (right) versus time for a TSCI patient. a
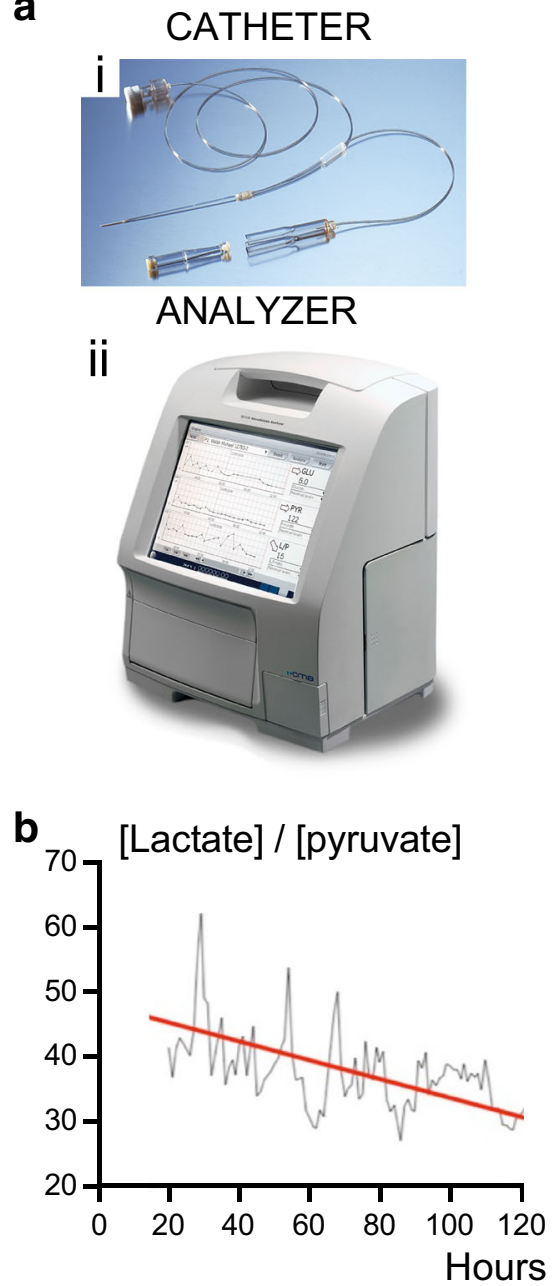

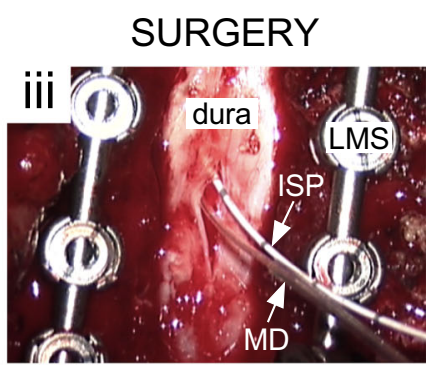

CT SCAN
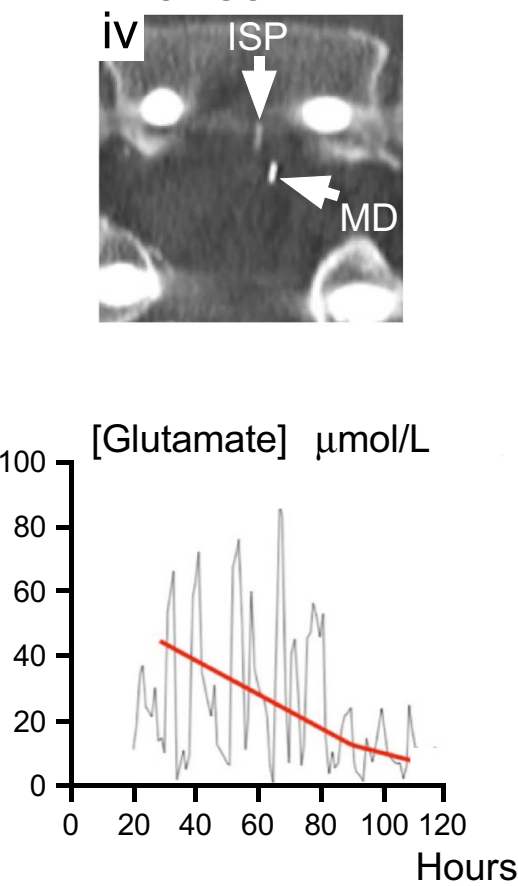


\section{Spinal Cord Blood Flow}

The impact of TSCI on SCBF in humans is poorly understood. Advanced MRI techniques are limited largely due to artifacts from cardiorespiratory motion as well as signal loss from the bone and the metalwork used to stabilize the spine. In a recent study, we investigated SCBF intraoperatively using laser speckle contrast imaging, a noninvasive technique in which a laser beam penetrates through the dorsal theca, $2-3 \mathrm{~mm}$ deep into the spinal cord, thus imaging blood flow in the dorsal columns [22]. We discovered 3 SCBF patterns, characterized by distinct injury site metabolic signatures: necrosis-penumbra, hyperperfusion, and patchy perfusion (Fig. 6). In some TSCI patients, increasing the MAP by $20 \mathrm{mmHg}$ increased the overall SCBF at the injury site, though blood flow increased in some regions but decreased in others. This phenomenon, termed blood pressure-induced local steal, may partly explain the detrimental effect of hyperperfusion. Further studies are required of real-time SCBF monitoring in the ICU as part of multimodality monitoring.

a

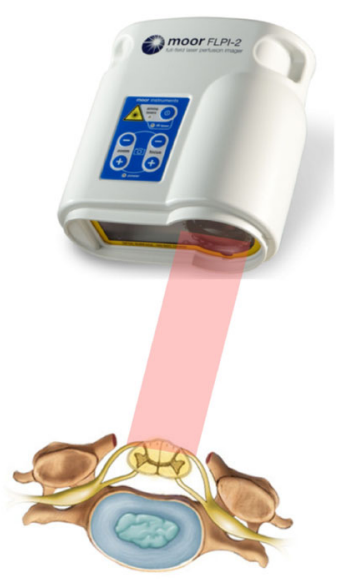

\section{Laser Speckle Imaging}

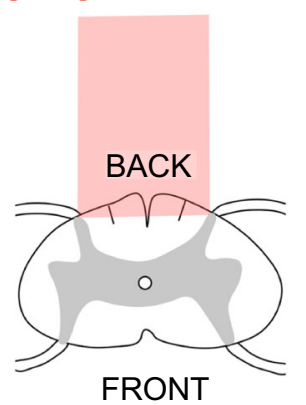

b
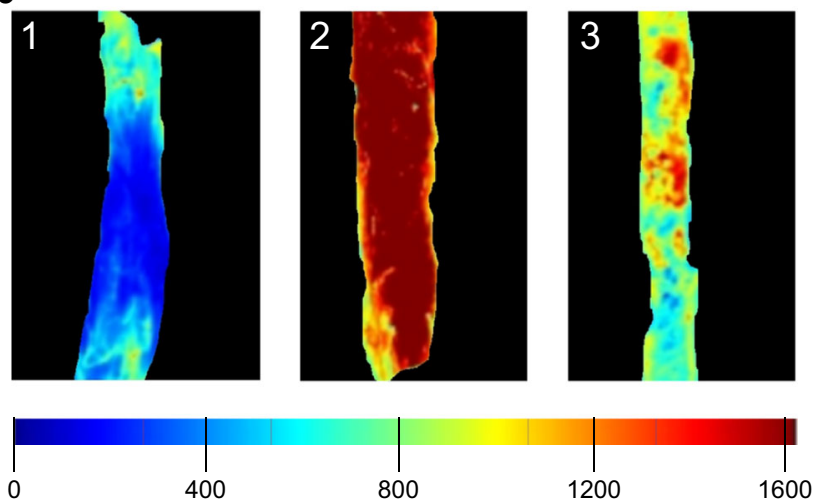

Blood flow (arbitrary units)

Fig. 6 Imaging spinal cord blood flow during surgery. (a) Schematic of setup. Laser speckle imager, infrared laser (red beam), and dorsal theca exposed after laminectomy. (b) Three patterns of spinal cord blood flow after injury (upper) termed as 1) necrosis-penumbra, 2) hyperperfusion, and 3) patchy perfusion. Spinal cord blood flow scale (bottom).

\section{Future Directions}

Monitoring spinal cord physiological and biochemical parameters from the injury site allows individualized, targeted perfusion therapy in TSCI patients, e.g., eliminating hypoperfusion or optimizing drug delivery. To date, monitoring data after TSCI have only been obtained in 1 center only (St. George's in London); it is important for other centers to independently validate these findings. An important finding is that the dura causes cord compression and thus a randomized controlled trial of expansion duroplasty for TSCI is being set up.

The probes used in our studies were designed for TBI; future designs may allow the probes to be inserted in TSCI patients in ICU without surgery. The ideal TSCI pressure probe should be radio-opaque and MRI compatible and have several measuring points to define the pressure profile of the injured cord. Such a probe will provide several ISP, sPRx, and SCPP readings simultaneously, which would require the concept of $\mathrm{SCPP}_{\text {opt }}$ to be redefined. An alternative to inserting probes intradurally is noninvasive, transcutaneous monitoring of hemoglobin oxygenation by near-infrared spectroscopy [40], although beam scatter by skin, muscle, bone, and metalwork may hinder such techniques. The recent availability of online MD, which allows continuous monitoring of extracellular tissue glucose, lactate, and pyruvate, may reveal novel pathological phenomena that occur at the timescale of seconds rather than hours. Finally, the monitoring techniques described here may also be applied in conditions associated with cord edema other than TSCI, e.g., neuromyelitis optica [83].

Acknowledgments We thank the Wings For Life Spinal Cord Research Foundation and the Neurosciences Research Foundation for funding our studies.

Required Author Forms Disclosure forms provided by the authors are available with the online version of this article.

Open Access This article is licensed under a Creative Commons Attribution 4.0 International License, which permits use, sharing, adaptation, distribution and reproduction in any medium or format, as long as you give appropriate credit to the original author(s) and the source, provide a link to the Creative Commons licence, and indicate if changes were made. The images or other third party material in this article are included in the article's Creative Commons licence, unless indicated otherwise in a credit line to the material. If material is not included in the article's Creative Commons licence and your intended use is not permitted by statutory regulation or exceeds the permitted use, you will need to obtain permission directly from the copyright holder. To view a copy of this licence, visit http://creativecommons.org/licenses/by/4.0/.

\section{References}

1. Lee BB, Cripps RA, Fitzharris M, Wing PC. The global map for traumatic spinal cord injury epidemiology: update 2011, global incidence rate. Spinal Cord 2014;52:110-116. 
2. SCI. info pages: https://www.sci-info-pages.com/facts.html 201015; Accessed 2019.

3. van Middendorp JJ, Goss B, Urquhart S, Atresh S, Williams RP, Schuetz M. Diagnosis and prognosis of traumatic spinal cord injury. Global Spine J 2011;1:1-8.

4. Werndle MC, Zoumprouli A, Sedgwick P, Papadopoulos MC. Variability in the treatment of acute spinal cord injury in the United Kingdom: results of a national survey. J Neurotrauma 2012;29:880 888.

5. Aarabi B, Akhtar-Danesh N, Chryssikos T et al. Efficacy of UltraEarly $(<12$ h), Early (12-24 h), and Late ( $>24-138.5$ h) Surgery with Magnetic Resonance Imaging-Confirmed Decompression in American Spinal Injury Association Impairment Scale Grades A, B, and C Cervical Spinal Cord Injury. J Neurotrauma 2019:In press.

6. Mayol M, Saavedra FM, Alcedo R, Murray G, Pastrana EA. Time of Surgery in the Outcome of Cervical Spinal Cord Injury: the University of Puerto Rico Experience. P R Health Sci J 2019;38:109-112.

7. Burke JF, Yue JK, Ngwenya LB et al. Ultra-Early $(<12$ Hours $)$ Surgery Correlates With Higher Rate of American Spinal Injury Association Impairment Scale Conversion After Cervical Spinal Cord Injury. Neurosurgery 2019;85:199-203.

8. El Tecle NE, Dahdaleh NS, Hitchon PW. Timing of Surgery in Spinal Cord Injury. Spine (Phila Pa 1976) 2016;41:E995-E1004.

9. Aarabi B, Olexa J, Chryssikos T et al. Extent of Spinal Cord Decompression in Motor Complete (American Spinal Injury Association Impairment Scale Grades A and B) Traumatic Spinal Cord Injury Patients: Post-Operative Magnetic Resonance Imaging Analysis of Standard Operative Approaches. J Neurotrauma 2019;36: 862-876.

10. Fehlings MG, Vaccaro A, Wilson JR et al. Early versus delayed decompression for traumatic cervical spinal cord injury: results of the Surgical Timing in Acute Spinal Cord Injury Study (STASCIS). PLoS One 2012;7:e32037.

11. Sweis R, Biller J. Systemic Complications of Spinal Cord Injury. Curr Neurol Neurosci Rep 2017;17:8.

12. Walters BC, Hadley MN, Hurlbert RJ et al. Guidelines for the management of acute cervical spine and spinal cord injuries: 2013 update. Neurosurgery 2013;60:82-91.

13. van Essen TA, den Boogert HF, Cnossen MC et al. Variation in neurosurgical management of traumatic brain injury: a survey in 68 centers participating in the CENTER-TBI study. Acta Neurochir (Wien) 2019;161:435-449.

14. Huijben JA, Volovici V, Cnossen MC et al. Variation in general supportive and preventive intensive care management of traumatic brain injury: a survey in 66 neurotrauma centers participating in the Collaborative European NeuroTrauma Effectiveness Research in Traumatic Brain Injury (CENTER-TBI) study. Crit Care 2018;22:90.

15. Abou El Fadl MH, O'Phelan KH. Management of Traumatic Brain Injury: An Update. Neurosurg Clin N Am 2018;29:213-221.

16. Hutchinson PJ, Kolias AG, Timofeev IS et al. Trial of Decompressive Craniectomy for Traumatic Intracranial Hypertension. N Engl J Med 2016;375:1119-1130.

17. Varsos GV, Werndle MC, Czosnyka ZH et al. Intraspinal pressure and spinal cord perfusion pressure after spinal cord injury: an observational study. J Neurosurg Spine 2015;23:763-771.

18. Werndle MC, Saadoun S, Phang I et al. Monitoring of spinal cord perfusion pressure in acute spinal cord injury: initial findings of the injured spinal cord pressure evaluation study*. Crit Care Med 2014;42:646-655.

19. Phang I, Zoumprouli A, Saadoun S, Papadopoulos MC. Safety profile and probe placement accuracy of intraspinal pressure monitoring for traumatic spinal cord injury: Injured Spinal Cord Pressure Evaluation study. J Neurosurg Spine 2016;25:398-405.

20. Zeiler FA, Donnelly J, Calviello L, Smielewski P, Menon DK, Czosnyka M. Pressure Autoregulation Measurement Techniques in Adult Traumatic Brain Injury, Part II: A Scoping Review of Continuous Methods. J Neurotrauma 2017;34:3224-3237.
21. Czosnyka M, Smielewski P, Timofeev I et al. Intracranial pressure: more than a number. Neurosurg Focus 2007;22:E10.

22. Gallagher MJ, Hogg FRA, Zoumprouli A, Papadopoulos MC, Saadoun S. Spinal Cord Blood Flow in Patients with Acute Spinal Cord Injuries. J Neurotrauma 2019;36:919-929.

23. Chen SL, Smielewski P, Czosnyka M, Papadopoulos MC, Saadoun S. Continuous Monitoring and Visualization of Optimum Spinal Cord Perfusion Pressure in Patients with Acute Cord Injury. J. Neurotrauma 2017;34:2941-2949.

24. Aries MJ, Wesselink R, Elting JW et al. Enhanced Visualization of Optimal Cerebral Perfusion Pressure Over Time to Support Clinical Decision Making. Crit Care Med 2016;44:e996-999.

25. Aries MJ, Czosnyka M, Budohoski KP et al. Continuous determination of optimal cerebral perfusion pressure in traumatic brain injury. Crit Care Med 2012;40:2456-2463.

26. Chen S, Gallagher MJ, Papadopoulos MC, Saadoun S. Non-linear Dynamical Analysis of Intraspinal Pressure Signal Predicts Outcome After Spinal Cord Injury. Front Neurol 2018;9:493.

27. Seely AJ, Macklem PT. Complex systems and the technology of variability analysis. Crit. Care 2004;8:R367-384.

28. Goldberger AL. Non-linear dynamics for clinicians: chaos theory, fractals, and complexity at the bedside. Lancet 1996;347:1312-1314.

29. Peng CK, Buldyrev SV, Havlin S, Simons M, Stanley HE, Goldberger AL. Mosaic organization of DNA nucleotides. Phys Rev E Stat Phys Plasmas Fluids Relat Interdiscip Topics 1994;49: 1685-1689.

30. Peng CK, Havlin S, Stanley HE, Goldberger AL. Quantification of scaling exponents and crossover phenomena in nonstationary heartbeat time series. Chaos 1995;5:82-87.

31. Costa M, Goldberger AL, Peng CK. Multiscale entropy analysis of biological signals. Phys. Rev. E Stat. Nonlin. Soft Matter Phys. 2005;71:021906.

32. Costa M, Goldberger AL, Peng CK. Multiscale entropy analysis of complex physiologic time series. Phys. Rev. Lett. 2002;89:068102.

33. Wolf A, Swift JB, Swinney HL, Vastano JA. Determining Lyapunov exponents from a time series. Physica 1985;16D:285-317.

34. Lacasa L, Luque B, Ballesteros F, Luque J, Nuno JC. From time series to complex networks: the visibility graph. Proc. Natl. Acad. Sci. U. S. A. 2008;105:4972-4975.

35. Pavlopoulos GA, Secrier M, Moschopoulos CN et al. Using graph theory to analyze biological networks. BioData Min 2011;4:10.

36. Kwon BK, Curt A, Belanger LM et al. Intrathecal pressure monitoring and cerebrospinal fluid drainage in acute spinal cord injury: a prospective randomized trial. J Neurosurg Spine 2009;10:181-193.

37. Hogg FRA, Gallagher MJ, Chen S, Zoumprouli A, Papadopoulos MC, Saadoun S. Predictors of Intraspinal Pressure and Optimal Cord Perfusion Pressure After Traumatic Spinal Cord Injury. Neurocrit Care 2019;30:421-428.

38. Squair JW, Belanger LM, Tsang A et al. Spinal cord perfusion pressure predicts neurologic recovery in acute spinal cord injury. Neurology 2017;89:1660-1667.

39. Hutchinson PJ, Kolias AG, Tajsic T et al. Consensus statement from the International Consensus Meeting on the Role of Decompressive Craniectomy in the Management of Traumatic Brain Injury: Consensus statement. Acta Neurochir (Wien) 2019;161:1261-1274.

40. Rashnavadi T, Macnab A, Cheung A, Shadgan A, Kwon BK, Shadgan B. Monitoring spinal cord hemodynamics and tissue oxygenation: a review of the literature with special focus on the nearinfrared spectroscopy technique. Spinal Cord 2019;57:617-625.

41. Gallagher MJ, Martín López D, Sheen HV et al. Heterogeneous effect of increasing spinal cord perfusion pressure on sensory evoked potentials recorded from acutely injured human spinal cord. 2019:Submitted.

42. Saadoun S, Papadopoulos MC. Spinal cord injury: is monitoring from the injury site the future? Crit Care 2016;20:308. 
43. Saadoun S, Chen S, Papadopoulos MC. Intraspinal pressure and spinal cord perfusion pressure predict neurological outcome after traumatic spinal cord injury. J Neurol Neurosurg Psychiatry 2017;88:452-453.

44. Phang I, Papadopoulos MC. Intraspinal Pressure Monitoring in a Patient with Spinal Cord Injury Reveals Different Intradural Compartments: Injured Spinal Cord Pressure Evaluation (ISCoPE) Study. Neurocrit Care 2015;23:414-418.

45. Papadopoulos MC. Intrathecal Pressure After Spinal Cord Injury. Neurosurgery 2015;77:E500.

46. Hogg FRA, Gallagher MJ, Kearney S, Zoumprouli A, Papadopoulos MC, Saadoun S. Acute spinal cord injury: monitoring the lumbar cerebrospinal fluid provides limited information about the injury site. Submitted 2019.

47. Saadoun S, Werndle MC, Lopez de Heredia L, Papadopoulos MC. The dura causes spinal cord compression after spinal cord injury. $\mathrm{Br}$ J Neurosurg 2016;30:582-584.

48. Phang I, Werndle MC, Saadoun S et al. Expansion duroplasty improves intraspinal pressure, spinal cord perfusion pressure, and vascular pressure reactivity index in patients with traumatic spinal cord injury: injured spinal cord pressure evaluation study. J Neurotrauma 2015;32:865-874.

49. Liu Z, Yang Y, He L et al. High-dose methylprednisolone for acute traumatic spinal cord injury: A meta-analysis. Neurology 2019;93: e841-e850.

50. Geisler FH, Dorsey FC, Coleman WP. Recovery of motor function after spinal-cord injury - a randomized, placebo-controlled trial with GM-1 ganglioside. N Engl J Med 1991;324:1829-1838.

51. Petitjean ME, Pointillart V, Dixmerias F et al. [Medical treatment of spinal cord injury in the acute stage]. Ann Fr Anesth Reanim 1998; 17:114-122.

52. Phang I, Zoumprouli A, Papadopoulos MC, Saadoun S. Microdialysis to Optimize Cord Perfusion and Drug Delivery in Spinal Cord Injury. Ann Neurol 2016;80:522-531.

53. Beraldo PS, Neves EG, Alves CM, Khan P, Cirilo AC, Alencar MR. Pyrexia in hospitalised spinal cord injury patients. Paraplegia 1993;31:186-191.

54. Colachis SC, 3rd, Otis SM. Occurrence of fever associated with thermoregulatory dysfunction after acute traumatic spinal cord injury. Am J Phys Med Rehabil 1995;74:114-119.

55. Sugarman B, Brown D, Musher D. Fever and infection in spinal cord injury patients. JAMA 1982;248:66-70.

56. McKinley W, McNamee S, Meade M, Kandra K, Abdul N. Incidence, etiology, and risk factors for fever following acute spinal cord injury. J Spinal Cord Med 2006;29:501-506.

57. Gallagher MJ, Zoumprouli A, Phang I et al. Markedly Deranged Injury Site Metabolism and Impaired Functional Recovery in Acute Spinal Cord Injury Patients With Fever. Crit Care Med 2018;46:1150-1157.

58. Dididze M, Green BA, Dietrich WD, Vanni S, Wang MY, Levi AD. Systemic hypothermia in acute cervical spinal cord injury: a casecontrolled study. Spinal Cord 2013;51:395-400.

59. Erecinska M, Thoresen M, Silver IA. Effects of hypothermia on energy metabolism in Mammalian central nervous system. J Cereb Blood Flow Metab 2003;23:513-530.

60. Chatzipanteli K, Alonso OF, Kraydieh S, Dietrich WD. Importance of posttraumatic hypothermia and hyperthermia on the inflammatory response after fluid percussion brain injury: biochemical and immunocytochemical studies. J Cereb Blood Flow Metab 2000;20:531-542.

61. Globus MY, Alonso O, Dietrich WD, Busto R, Ginsberg MD. Glutamate release and free radical production following brain injury: effects of posttraumatic hypothermia. J Neurochem 1995;65: 1704-1711.

62. Batchelor PE, Kerr NF, Gatt AM et al. Hypothermia prior to decompression: buying time for treatment of acute spinal cord injury. $\mathrm{J}$ Neurotrauma 2010;27:1357-1368.

63. Shibuya S, Miyamoto O, Janjua NA, Itano T, Mori S, Norimatsu H. Post-traumatic moderate systemic hypothermia reduces TUNEL positive cells following spinal cord injury in rat. Spinal Cord 2004;42:29-34.

64. Chatzipanteli K, Yanagawa Y, Marcillo AE, Kraydieh S, Yezierski RP, Dietrich WD. Posttraumatic hypothermia reduces polymorphonuclear leukocyte accumulation following spinal cord injury in rats. J Neurotrauma 2000;17:321-332.

65. Yu CG, Jimenez O, Marcillo AE et al. Beneficial effects of modest systemic hypothermia on locomotor function and histopathological damage following contusion-induced spinal cord injury in rats. $\mathrm{J}$ Neurosurg 2000;93:85-93.

66. Lo TP, Jr., Cho KS, Garg MS et al. Systemic hypothermia improves histological and functional outcome after cervical spinal cord contusion in rats. J Comp Neurol 2009;514:433-448.

67. Andrews PJ, Sinclair HL, Rodriguez A et al. Hypothermia for Intracranial Hypertension after Traumatic Brain Injury. N Engl J Med 2015;373:2403-2412.

68. Clifton GL, Miller ER, Choi SC et al. Lack of effect of induction of hypothermia after acute brain injury. N Engl J Med 2001;344:556-563.

69. Lewis SR, Evans DJ, Butler AR, Schofield-Robinson OJ, Alderson P. Hypothermia for traumatic brain injury. Cochrane Database Syst Rev 2017;9:CD001048.

70. Hansebout RR, Hansebout CR. Local cooling for traumatic spinal cord injury: outcomes in 20 patients and review of the literature. J Neurosurg Spine 2014;20:550-561.

71. Bricolo A, Ore GD, Da Pian R, Faccioli F. Local cooling in spinal cord injury. Surg Neurol 1976;6:101-106.

72. Cappuccino A, Bisson LJ, Carpenter B, Snyder K, Cappuccino H. Systemic Hypothermia as Treatment for an Acute Cervical Spinal Cord Injury in a Professional Football Player: 9-Year Follow-Up. Am J Orthop (Belle Mead NJ) 2017;46:E79-E82.

73. Hutchinson PJ, Jalloh I, Helmy A et al. Consensus statement from the 2014 International Microdialysis Forum. Intensive Care Med 2015;41:1517-1528.

74. Nangunoori R, Maloney-Wilensky E, Stiefel M et al. Brain tissue oxygen-based therapy and outcome after severe traumatic brain injury: a systematic literature review. Neurocrit Care 2012;17: 131-138.

75. Mathieu F, Khellaf A, Ku JC, Donnelly J, Thelin EP, Zeiler FA. Continuous Near-Infrared Spectroscopy Monitoring in Adult Traumatic Brain Injury: A Systematic Review. J Neurosurg Anesthesiol 2019:In press.

76. Hartings JA, Bullock MR, Okonkwo DO et al. Spreading depolarisations and outcome after traumatic brain injury: a prospective observational study. Lancet Neurol 2011;10:1058-1064.

77. Abrahamsson P, Aberg AM, Johansson G, Winso O, Waldenstrom A, Haney M. Detection of myocardial ischaemia using surface microdialysis on the beating heart. Clin Physiol Funct Imaging 2011;31:175-181.

78. Abrahamsson P, Johansson G, Aberg AM, Winso O, Blind PJ. Outcome of microdialysis sampling on liver surface and parenchyma. J Surg Res 2016;200:480-487.

79. Chen S, Phang I, Zoumprouli A, Papadopoulos MC, Saadoun S. Metabolic profile of injured human spinal cord determined using surface microdialysis. J Neurochem 2016;139:700-705.

80. Cirillo D, Valencia A. Big data analytics for personalized medicine. Curr Opin Biotechnol 2019;58:161-167.

81. Blinowska KJ, Kus R, Kaminski M. Granger causality and information flow in multivariate processes. Phys Rev E Stat Nonlin Soft Matter Phys 2004;70:050902.

82. Sugihara G, May R, Ye $\mathrm{H}$ et al. Detecting causality in complex ecosystems. Science 2012;338:496-500.

83. Papadopoulos MC, Verkman AS. Aquaporin 4 and neuromyelitis optica. Lancet Neurol 2012;11:535-544. 